\title{
Analisis Fikih Muamalah Terhadap Transaksi Transfer Dana Antar Bank Melalui Aplikasi Flip
}

\author{
Siti Widya Umiyati ${ }^{1 *}$, Selvi Nur Fitriah ${ }^{2}$
}

\section{Abstrak}

Penelitian ini bertujuan untuk menganalisis: pertama, praktik transfer dana antar bank melalui aplikasi Flip, kedua, analisis fikih muamalah terhadap transaksi transfer antar bank melalui aplikasi Flip. Metode penelitian yang digunakan dalam penelitian ini adalah penelitian lapangan dengan pendekatan kualitatif. Hasil penelitian ini menunjukkan bahwa: Pertama, praktik transfer dana antar bank melalui aplikasi Flip telah diterapkan dengan tepat menggunakan akad wakalah, mekanisme yang digunakan untuk transfer dana yaitu dengan mengisi data permintaan transfer, melakukan transfer sejumlah nominal yang ingin dikirim ditambah dengan kode unik ke rekening bank Flip yang sama dengan bank pengguna, pengguna tidak merasa keberatan dengan adanya penambahan kode unik, pengguna rela menambahkan kode unik karena nominal kode unik lebih kecil daripada biaya administrasi konvensional. Kedua, analisis fikih muamalah terkait hukum transaksi transfer dana antar bank ialah boleh karena sudah terhindar dari transaksi riba, maisir, gharar, tadlis serta terdapat kemaslahatan untuk meringankan transaksi transfer antar bank yang berbeda.

Kata Kunci: Kajian Fikih Muamalah; Transfer Dana; Aplikasi Flip

\section{Abstract}

This study aims to analyze: first, the practice of transferring funds between banks through the Flip application, second, the figh muamalah analysis of interbank transfer transactions through the Flip application. The research method used in this research is field research with a qualitative approach. The results of this study indicate that: First, the practice of transferring funds between banks through the Flip application has been properly implemented using a wakalah contract, the mechanism used for transferring funds is by filling in transfer request data, transferring a nominal amount that you want to send plus a unique code to the account. Flip bank is the same as the user's bank, the user does not object to the addition of a unique code, the user is willing to add a unique code because the nominal unique code is smaller than conventional administration fees. Second, the figh muamalah analysis related to the law of interbank fund transfer transactions is permissible because it has avoided usury, maisir, gharar, tadlis transactions and there are benefits to ease transfer transactions between different banks.

\footnotetext{
${ }^{1}$ Institut Ilmu Al-Qur'an, Jakarta

${ }^{2}$ Institut Ilmu Al-Qur'an, Jakarta

Analisis Fikih Muamalah Terhadap Transaksi Transfer Dana Antar Bank

Melalui Aplikasi Flip
}

Siti Widya Umiyati, Selvi Nur Fitriah 
Keywords: Muamalah Figh Study; Transfer of funds; Flip App

\section{PENDAHULUAN}

Flip merupakan start-up business yang menjalankan kegiatan usaha jasa transfer dana antar bank tanpa biaya administrasi berupa layanan digital yang dapat diakses melalui smartphone android/iOS atau website. Fitur layanan yang ditawarkan juga cukup banyak, di antaranya transfer dana antar bank tanpa biaya administrasi (kirim uang gratis), beli pulsa, isi paket data, listrik PLN dan refund. Jumlah pengguna Flip yang sudah mencapai jutaan orang dan terus bertambah tiap tahunnya. Pada awal beroperasi Flip hanya memiliki 40 orang pengguna yang mempercayai transaksinya kepada Flip. Kemudian pada Juni 2016 pengguna Flip menjadi 20.000 orang dan awal tahun 2017 terdapat 38.000 pengguna Flip, hingga saat ini mencapai 3,5 juta pengguna Flip (Instagram Flip, Maret 2021).

Flip berperan sebagai perantara transaksi transfer dana antar bank, yang mana jika pengguna Flip ingin melakukan transaksi transfer dana beda bank tanpa biaya administrasi, pengguna harus mentransfer terlebih dahulu sejumlah uang ditambah dengan nominal kode unik transaksi ke rekening Flip yang sama dengan bank milik pengguna, kemudian jika transfer berhasil maka Flip akan meneruskan transfer ke nomor rekening tujuan si pengguna menggunakan saldo rekening Flip yang sama dengan bank tujuan si pengguna. Untuk meneruskan transfer dana ke rekening tujuan, Flip sudah menyediakan danadananya di rekening lain. Maka dengan begitu Flip dapat membebaskan biaya administrasi transfer antar bank. Jika dilihat dari alurnya, transaksi ini mengandung unsur akad yang memiliki arti "ikatan" (pengencangan atau penguatan) antara beberapa pihak dalam hal tertentu, baik ikatan itu bersifat konkret maupun abstrak, baik dari satu sisi maupun dua sisi (Wahbah Az-Zuhaili, 2011:520). Akad yang diterapkan dalam transaksi seperti ini dalam Islam dapat dikatakan wakalah. Wakalah diartikan sebagai perwakilan, penyerahan, pendelegasian, pemberian mandat (power of attorney) atau akad pelimpahan kekuasaan oleh satu pihak kepada pihak lain dalam halhal yang boleh diwakilkan (Sholihin, 2010:888). 
Banyak masyarakat yang menggunakan aplikasi Flip, khususnya layanan transfer dana antar banyak secara gratis. Namun, pelaksanaan transfer dana beda bank tanpa biaya administrasi melalui aplikasi Flip belum sepenuhnya sesuai dengan kriteria dalam PBI No.19/12/PBI/2017 tentang Penyelenggaraan Teknologi Finansial dan belum ada perlindungan konsumen jika terjadi kesalahan dalam meneruskan transfer ke rekening tujuan, selain itu masih terdapat perilaku bisnis yang tidak dianjurkan dalam Islam, yaitu berupa proses transfer yang memakan waktu lama karena mengalami dua kali proses pengiriman, ketidakjelasan waktu dalam penyerahan kode unik yang diberikan ke pengguna Flip dan kezaliman dalam bisnis antar start-up di bidang transfer dana (Dwimurti, 2020:1-15). Adapun kode unik yang dimaksud dalam transaksi transfer dana melalui aplikasi Flip adalah nominal yang ditambahkan pihak Flip berupa tiga digit angka terakhir transfer dan digunakan sebagai identitas untuk membedakan setiap transaksi pengguna agar mudah diproses dan pada akhirnya kode unik tersebut akan dikembalikan ke saldo pengguna Flip dan bisa digunakan untuk beli pulsa atau ditarik ke rekening pengguna Flip jika saldonya sudah mencapai Rp10.000,00. Penetapan kode unik ini dikhawatirkan menyebabkan adanya ketidakjelasan (gharar) saat transaksi. Konsekuensi jika pengguna tidak menambahkan kode unik tersebut maka transaksi tidak bisa diproses dan dibatalkan. Ibnu Taimiyah menjelaskan bahwa pelarangan terhadap transaksi gharar didasarkan kepada larangan Allah Swt. atas pengambilan harta atau hak milik orang lain secara tidak benar (batil) (Hosen, 2009:55).

\section{LANDASAN TEORITIS \\ Wakalah}

\section{Pengertian Wakalah}

Secara etimologi kata wakalah berasal dari wazan wakala-yakiluwaklan yang berarti menyerahkan atau mempercayakan (Munawwir, 1997:1579). Wakalah juga berarti al-hifzh (penjagaan, perlindungan, pemeliharaan) (Munawwir, 1997:279) dan al-tafwidh (pemberian kuasa) (Munawwir, 1997:1078). Sedangkan secara terminologi, wakalah didefinisikan sebagai perjanjian antara seseorang (pemberi kuasa) dengan orang lain (pihak yang menerima kuasa) untuk melakukan 
tugas pendelegasian tertentu atas nama pemberi kuasa (Adam, 2017:295).

Adapun pengertian wakalah menurut Kompilasi Hukum Ekonomi Syariah (KHES) Pasal 20 Ayat 19, yaitu pemberian kuasa kepada pihak lain untuk mengerjakan sesuatu (Margono, 2009:11). Kuasa dalam konteks ini kuasa untuk menjalankan kewajiban dan kuasa untuk menerima hak. Kuasa untuk menjalankan kewajiban, seperti seseorang mewakilkan kepada orang lain untuk membayar utang. Kuasa untuk menerima hak misalnya mewakilkan untuk menerima pembayaran utang (Adam, 2009:295).

Dengan demikian penulis menyimpulkan bahwa akad wakalah adalah akad perwakilan antara pemberi kuasa dengan penerima kuasa untuk melaksanakan suatu urusan yang boleh diwakilkan atas nama pemberi kuasa dan dilakukan selama yang mewakilkan (muwakkil) masih hidup.

2. Dasar Hukum Wakalah

a. Al-Qur'an

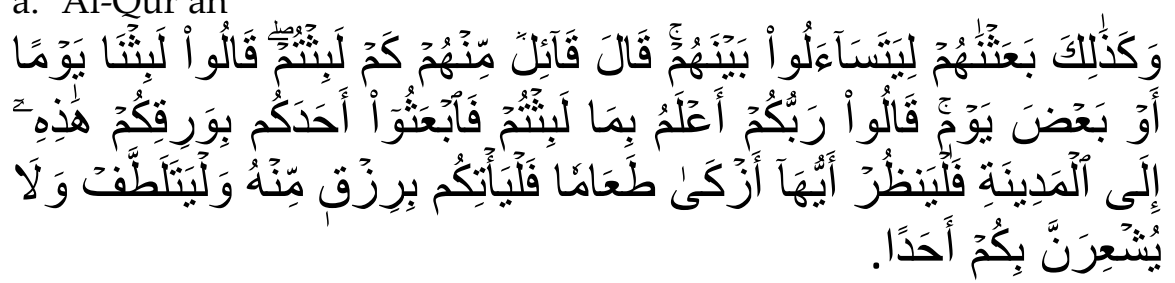

"Dan demikianlah Kami bangunkan mereka agar mereka saling bertanya di antara mereka sendiri. Berkatalah salah seorang di antara mereka: Sudah berapa lamakah kamu berada (disini?)". Mereka menjawab: "Kita berada (disini) sehari atau setengah hari". Berkata (yang lain lagi): "Tuhan kamu lebih mengetahui berapa lamanya kamu berada (di sini). Maka suruhlah salah seorang di antara kamu untuk pergi ke kota dengan membawa uang perakmu ini, dan hendaklah dia lihat manakah makanan yang lebih baik, maka hendaklah ia membawa makanan itu untukmu, dan hendaklah ia berlaku lemah-lembut dan janganlah sekali-kali menceritakan halmu kepada seorangpun." (QS. AlKahfi [18]:19)

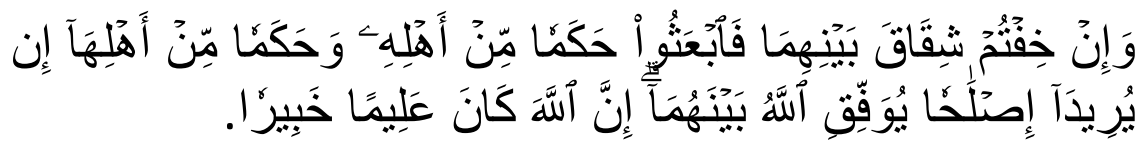

Analisis Fikih Muamalah Terhadap Transaksi Transfer Dana Antar Bank Melalui Aplikasi Flip 
"Dan jika kamu khawatirkan ada persengketaan antara keduanya, maka kirimlah seorang hakam dari keluarga laki-laki dan seorang hakam dari keluarga perempuan. Jika kedua orang hakam itu bermaksud mengadakan perbaikan, niscaya Allah memberi taufik kepada suami-isteri itu. Sesungguhnya Allah Maha Mengetahui lagi Maha Mengenal." (QS. An-Nisa [4]:35)

Ayat-ayat di atas tidak menyebutkan wakalah secara eksplisit, namun apa yang tertulis dan dikisahkan dalam ayat-ayat di atas berkaitan dengan wakalah. Lafaz-lafaz berupa kata perintah dalam ayat di atas menunjukkan adanya perwakilan atas wakalah.

b. Hadis

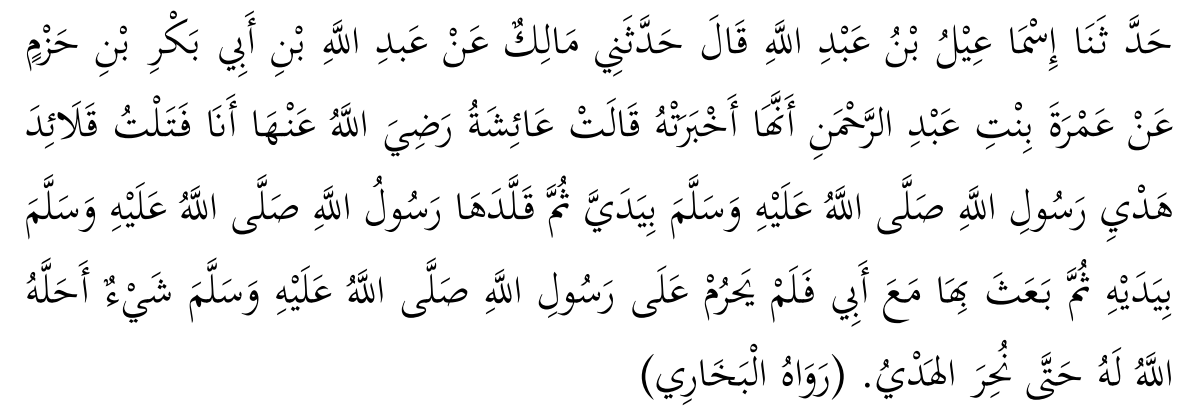

"Telah meriwayatkan kepada kami Isma'il bin 'Abdullah berkata, telah meriwayatkan kepadaku Malik dari 'Abdullah bin Abu Bakar bin Hazm dari 'Amrah binti 'Abdurrahman bahwa dia mengatakan kepadanya, 'Aisyah ra. berkata: "Aku mengikat tali kepada hewan kurban Rasulullah Saw. dengan tanganku kemudian Rasulullah Saw. mengikatnya kembali dengan tangan nya dan mengirimkannya kepada ayahku, hewan kurban disembelih." (HR. alBukhari, No Hadist 2.317, hal. 557).

Dalam kehidupan sehari-hari, Rasulullah Saw. telah mewakilkan kepada orang lain untuk mengerjakan berbagai urusan, antara lain yaitu mewakilkan dalam pembagian sedekah, mewakilkan dalam pembayaran utang, mewakilkan pengurusan hewan kurban, dan lain sebagainya. Itulah beberapa contoh adanya wakalah pada masa Rasulullah Saw.

c. Ijma'

Para Imam telah sepakat tentang kebolehan akad wakalah. Akad wakalah dibolehkan karena adanya kebutuhan (al-hajjah) untuk melakukannya dan terkadang seseorang tidak mampu untuk 
melaksanakan kemaslahatan dirinya secara keseluruhan. Oleh sebab itulah akad wakalah dibolehkan karena merupakan bagian dari perbuatan tolong menolong dalam kebaikan dan ketakwaan (AzZuhaili, 2011:595). Allah Swt. berfirman:

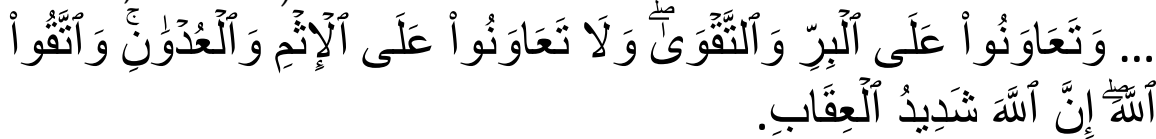

"...dan tolong-menolonglah kamu dalam (mengerjakan) kebajikan dan takwa, dan jangan tolong-menolong dalam berbuat dosa dan pelanggaran." (QS. Al-Ma'idah [5]:2).

Ayat di atas merupakan prinsip dasar dalam menjalin kerjasama dengan siapa pun. Selama tujuannya adalah kebajikan dan ketakwaan (Shihab, 2002:14).

d. Kaidah

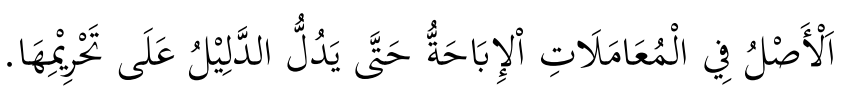

"Hukum asal semua muamalah adalah boleh, hingga ada dalil yang menunjukkan keharamannya."

Dari kaidah di atas dapat diketahui bahwa pada dasarnya segala sesuatu dalam muamalah adalah mubah (dibolehkan), kecuali ada dalil yang mengharamkannya. Adapun sesuatu yang tidak ada keterangan halal haramnya, maka kembali kepada hukum asal yakni halal (mubah) (Soemitra, 2019:68). Oleh sebab itu, dapat dimaknai bahwa hukum Islam memberi kesempatan yang luas dalam perkembangan bentuk dan macam muamalah baru, yang di zaman Nabi tidak terjadi sesuai dengan perkembangan kebutuhan hidup manusia (Juanda, 2019:68). Jadi bentuk transaksi apapun, Islam tidak melarang selama tidak ada tindakan yang diharamkan dalam agama. Semua hal yang Allah Swt. haramkan pasti ada sebab dan hikmahnya.

3. Rukun dan Syarat Wakalah

a. Rukun Wakalah

Menurut jumhur ulama, wakalah mempunyai empat rukun, yakni:

1) orang yang mewakilkan (muwakkil)

2) orang yang mewakili (wakil)

3) objek wakalah atau sesuatu yang diwakilkan (al-muwakkal fih)

Analisis Fikih Muamalah Terhadap Transaksi Transfer Dana Antar

Bank Melalui Aplikasi Flip

Siti Widya Umiyati, Selvi Nur Fitriah 
4) sighat (ucapan atau perbuatan yang menunjukkan ijab dan kabul) (Az-Zuhaili, 2011:591).

b. Syarat-syarat Wakalah

1) Orang yang mewakilkan (muwakkil), disyaratkan:

a) Pemilik kewenangan untuk melakukan tindakan terhadap sesuatu yang dia wakilkan.

b) Cakap bertindak hukum atau mukallaf dan sempurna akalnya. (Az-Zuhaili, 2011:596).

2) Orang yang mewakili (wakil), disyaratkan:

a) Berakal, mumayyiz, dan cakap hukum.

b) Mengetahui objek yang akan diwakilkan.

c) Harus jelas dan pasti (Adam, 2017:301).

3) Objek wakalah merupakan pekerjaan atau sesuatu yang harus dilakukan oleh wakil atas nama pihak yang mewakilkan (muwakkil). Adapun objek wakalah (muwakkal bih/muwakkal fih), disyaratkan:

a) Muwakkal fih bukan hal-hal yang kepemilikannya terbuka untuk umum, tanpa adanya batasan kepemilikan.

b) Muwakkal fih adalah milik muwakkil.

c) Muwakkal fih tersebut diketahui sebagian aspeknya, yang bertujuan agar ketidakjelasan dan ketidakpastian di dalamnya tidak berat. Hal tersebut disyaratkan oleh para ulama Syafi'iyah.

d) Muwakkal fih bukan berupa perintah untuk mengutang dari orang lain. Perwakilan dalam hal ini hanya sah apabila dilakukan dengan cara pengutusan, yaitu wakil berkata, "Fulan mengutus saya untuk utang uang sekian kepada Anda." (Az-Zuhaili, 2011:598).

e) Muwakkal fih secara syariah bisa diwakili oleh orang lain, yakni semua urusan keuangan dan yang lainnya yang bisa diwakili oleh orang lain.

4) Sighat adalah perjanjian yang biasanya berupa kesepakatan yang diawali proses penawaran (ijab) dan penerimaan (kabul). Harus munajazah, yaitu akad bersifat efektif pada saat akad wakalah dilakukan atau bersifat ke depan (mustaqbal), yaitu akad wakalah dilakukan sekarang tetapi berlaku 
efektifnya pada masa yang akan dating (Mubarok \& Hasanuddin, 2017:173).

\section{HASIL DAN PEMBAHASAN}

\section{Transfer Dana Antar Bank Tanpa Biaya Administrasi Melalui Aplikasi Flip}

Alur transaksi transfer dana melalui aplikasi Flip yaitu sebagai berikut:

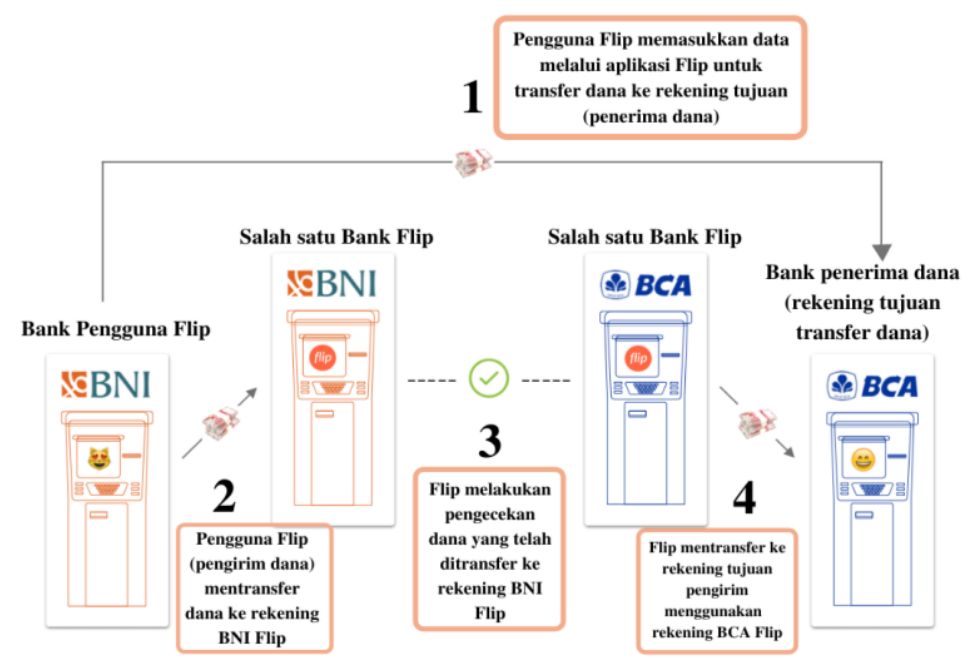

Gambar 1. Alur Transaksi Transfer Dana Antar Bank Melalui Flip

Transfer dana antar bank tanpa biaya administrasi merupakan suatu layanan untuk mengirimkan uang antar bank (bank yang berbeda) secara gratis dengan menggunakan fitur kirim uang gratis yang terdapat di aplikasi Flip. Transfer dana antar bank dapat dilakukan oleh pengguna Flip yang sudah memverifikasi data diri maupun pengguna yang belum memverifikasi data diri. Cara untuk melakukan transfer antar bank melalui Flip juga cukup mudah, yaitu dengan membuka aplikasi Flip, pilih kirim uang gratis, pilih bank tujuan, masukkan nomor rekening tujuan, masukkan nominal. Lalu pilih dari bank mana pengguna ingin transfer. Setelah itu akan muncul nominal dan nomor rekening Flip sesuai dengan rekening milik

Analisis Fikih Muamalah Terhadap Transaksi Transfer Dana Antar

Bank Melalui Aplikasi Flip Siti Widya Umiyati, Selvi Nur Fitriah 
pengguna. Kemudian transfer, pilih sudah transfer. Selanjutnya tunggu 10 menit sudah ada bukti transfernya (Wawancara Pengguna Flip, 12 Juli 2021).

Untuk melakukan transfer dana antar bank tanpa biaya administrasi, pengguna Flip harus mendaftarkan akun terlebih dahulu. Apabila pengguna sudah mempunyai akun, maka pengguna bisa melakukan transaksi transfer. Namun, untuk batas maksimal nominal yang ditawarkan masih terbatas, yaitu Rp500.000,00/transaksi. Oleh sebab itu, pengguna diharapkan untuk memverifikasi akun Flip agar dapat menikmati layanan yang lebih banyak. Adapun untuk mengantisipasi kegagalan transaksi Flip juga menyediakan fitur refund untuk mengembalikan dana pengguna yang sudah dikirim ke rekening Flip dan fitur tarik saldo untuk pengguna yang ingin menarik saldo Flip ke rekening pengguna Flip.

Praktik transfer dana antar bank melalui aplikasi Flip yang terjadi di lapangan merupakan layanan yang menjembatani dalam bidang transfer dana yang dilakukan oleh start-up dalam bentuk melaksanakan pengiriman uang pengguna kepada tujuan transfer yang ditujukan oleh pengguna selaku pengirim uang yang mewakilkan kepada Flip agar tidak terkena biaya administrasi. Pada praktiknya, aplikasi Flip berperan sebagai wakil pengguna untuk mentransfer ke pihak tujuan transfer yang memiliki rekening bank berbeda dengan rekening yang dimiliki pengguna. Adapun skemanya yaitu pengguna menitipkan uang sebesar nominal yang ingin ditransfer ditambah kode unik kepada Flip untuk ditransfer ke rekening tujuan. Kemudian, Flip menggunakan uang sejumlah nominal transfer yang diajukan oleh pengguna di rekening bank yang lain untuk diserahkan ke rekening bank tujuan.

Sebelum melakukan transfer dana melalui aplikasi Flip, tentunya pengguna harus mempunyai akun pada aplikasi Flip terlebih dahulu. Pengguna yang sudah mempunyai akun Flip dapat melakukan transaksi transfer, namun dengan batas nominal transaksi Rp500.000,00/hari. Oleh sebab itu, pengguna diharapkan untuk memverifikasi akun Flip agar dapat menikmati layanan yang lebih banyak dan dengan nominal transaksi maksimal Rp5.000.000,00/hari.

Adapun mekanisme untuk melakukan transfer dana antar bank tanpa biaya administrasi melalui Flip juga cukup mudah, yaitu dengan

50 Analisis Fikih Muamalah Terhadap Transaksi Transfer Dana Antar Bank Melalui Aplikasi Flip

Siti Widya Umiyati, Selvi Nur Fitriah 
membuka aplikasi Flip, pilih menu kirim uang gratis, pilih bank tujuan transfer, masukkan nomor rekening tujuan, masukkan nominal yang ingin ditransfer. Lalu pilih metode pembayaran atau bank yang sesuai dengan bank milik pengguna. Setelah itu akan muncul nominal transfer beserta kode unik yang harus ditransfer ke rekening bank Flip yang sama bank milik pengguna. Kemudian pilih transfer (pengirim dapat mentransfer melalui ATM/internet banking/m-banking). Setelah transfer ke rekening Flip selesai dilanjut dengan pilih sudah transfer. Selanjutnya tunggu sekitar 10 menit untuk proses pengecekan, hingga muncul notifikasi bahwa transaksi telah berhasil yang dikirim ke aplikasi Flip dan e-mail pengguna. Pada dasarnya transfer dana melalui aplikasi Flip sama halnya sebagaimana transfer pada umumnya, hanya saja pengguna perlu menambahkan kode unik saat transfer ke Flip. Kode unik ini memiliki fungsi sebagai identitas transaksi para pengguna yang bertujuan agar memudahkan Flip dalam memproses transaksi. Di mana kode unik tersebut akan dikembalikan kepada pengguna berupa saldo deposit di akun aplikasi Flip yang dapat dipakai untuk pembelian pulsa, paket data ataupun ditarik ke rekening bank pengguna jika telah mencapai Rp10.000,00. Para pengguna rela dan tidak merasa keberatan dengan adanya kode unik. Hal ini disebabkan kode unik yang ditetapkan relatif kecil jika dibandingkan dengan biaya administrasi transfer dana antar bank yang berbeda, pada umumnya biaya transfer dana tersebut sekitar Rp4.000,00 sampai dengan Rp6.500,00. Selain itu kode unik tersebut juga dapat dicairkan atau ditarik ke rekening pengguna.

\section{Analisis Fikih Muamalah Terhadap Transaksi Transfer Dana Antar Bank Melalui Aplikasi Flip}

Sebagaimana penjelasan yang sudah dikemukakan pada pemaparan sebelumnya bahwa dalam kegiatan muamalah dalam konteks ekonomi terdapat larangan yang terkandung dalam Al-Qur'an yang membatasi kegiatan ekonomi termasuk kegiatan transaksi transfer dana, seperti larangan riba. Pada praktik transaksi transfer dana antar bank tanpa biaya administrasi melalui aplikasi Flip sudah terhindar dari riba, hal ini dapat dilihat dari akad yang digunakan

Analisis Fikih Muamalah Terhadap Transaksi Transfer Dana Antar Bank Melalui Aplikasi Flip Siti Widya Umiyati, Selvi Nur Fitriah 
antara pengguna dengan pihak Flip ialah akad wakalah, implementasi akad wakalah yaitu pihak Flip berperan sebagai wakil pengguna untuk mentransfer ke pihak tujuan transfer yang memiliki rekening bank berbeda dengan rekening bank milik pengguna agar tidak terkena biaya administrasi. Adapun mengenai hukum kode unik ini tidak termasuk riba karena bukan diperoleh dari akad utang piutang. Sebagaimana Ustaz Ammi Nur Baits menyatakan bahwa kode unik ketika transfer diartikan sebagai identitas yang nilainya kecil. Pada hakikatnya, kode unik adalah perubahan harga yang disepakati antara penjual dengan pembeli. Kode unik transfer tidak termasuk riba, sebab kode unik ditambahkan bukan karena akad utang piutang, tetapi ditambahkan dari akad jual beli. Selain itu, penambahan kode unik dilakukan atas saling rida sebagai penambahan harga dan diperbolehkan selama kedua belah pihak saling rida (16 Maret 2020). Kode unik pembayaran merupakan nominal yang ditambahkan secara acak sebagai identitas dari transaksi pembayaran yang terletak di akhir total pembayaran (Solihin, 2021). Dalam praktiknya, kode unik di Flip berjumlah 2 sampai dengan 3 digit yang berfungsi sebagai pengenal dari sebuah tansaksi agar menjadi pembeda dari transaksi lainnya. Penambahan kode unik merupakan hal lazim yang menjadi salah satu syarat yang harus terpenuhi dalam transaksi pembayaran. Sebelum melakukan transfer dana, pengguna juga diharuskan mendaftar akun terlebih dahulu yang bertujuan untuk memberitahu proses berlangsungnya suatu transaksi dan apabila transaksi gagal, dana dapat dikembalikan ke akun tersebut. Begitu juga dengan kode unik yang merupakan salah satu syarat untuk mempermudah proses transaksi, maka penambahan kode unik tersebut tidak termasuk riba (Bincang Syariah, 2021).

Kemudian kode unik termasuk gharar yang diperbolehkan karena termasuk kategori gharar yang sedikit, gharar bukan dalam inti objek akad dan gharar karena adanya kebutuhan. Dalam implementasinya, kode unik itu dijadikan sebagai pelengkap transaksi, yaitu salah satu syarat dari suatu transaksi transfer dana melalui aplikasi Flip, dimana syarat tersebut dilakukan untuk menguatkan transaksi dan dapat memberikan kemaslahatan dalam pengenalaan identitas transaksi. Selain itu, pengguna juga sudah menyetujui adanya kode unik dan 
sudah merelakan transfer dengan menambahkan kode unik, karena kode unik yang harus ditransfer jumlahnya tidak banyak.

Sebagaimana firman Allah dalam QS. An-Nisa [4]:29, yaitu:

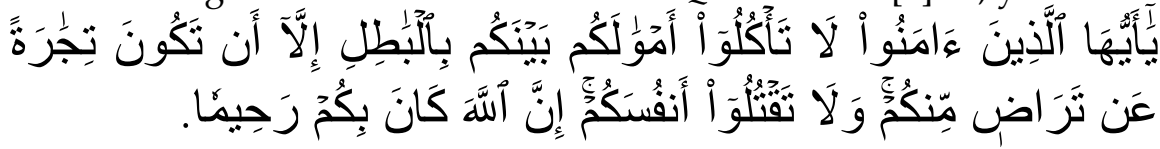

"Hai orang-orang yang beriman, janganlah kamu saling memakan harta sesamamu dengan jalan yang batil, kecuali dengan jalan perniagaan yang berlaku dengan suka sama-suka di antara kamu. Dan janganlah kamu membunuh dirimu; sesungguhnya Allah adalah Maha Penyayang kepadamu." (QS. An-Nisa [4]:29)

Selanjutnya untuk penyerahan kode unik yang belum mencapai Rp10.000,00 pengguna dapat melakukan pengisian saldo ke akun pengguna dengan minimal pengisian saldo Rp10.000,00, setelah saldo masuk ke akun pengguna, pengguna dapat melakukan penarikan saldo. Dengan demikian tidak terjadi gharar dalam penyerahan kode unik, karena kode unik langsung dapat ditarik bersama dengan saldo yang ada di akun Flip pengguna.

Kode unik juga tidak mengandung unsur maisir, karena pihak Flip menentukan Flip berdasarkan antrean pengguna dan nantinya kode unik tersebut juga dikembalikan ke saldo deposit akun Flip pengguna. Kemudian dalam pengiriman ke rekening tujuan pun Flip, selalu sesuai dengan permintaan pengguna. Dalam hal ini, Flip tidak melakukan tadlis, karena masing-masing pihak saling mengetahui berlangsungnya transaksi.

Kebolehan transaksi transfer dana antar bank melalui aplikasi Flip tidak cukup dengan terhindar dari riba, maisir, gharar dan tadlis, tetapi juga dilihat dari kemaslahatannya bagi umat. Adapun kemaslahatan yang terdapat pada transaksi transfer dana antar bank tanpa biaya administrasi yaitu meringankan masyarakat dalam melakukan kegiatan pengiriman uang antar rekening ke bank yang berbeda, sehingga pengguna dapat melakukan transaksi transfer dana dengan mudah, murah, dan dapat menghemat pengeluaran.

Analisis Fikih Muamalah Terhadap Transaksi Transfer Dana Antar

Bank Melalui Aplikasi Flip

Siti Widya Umiyati, Selvi Nur Fitriah 
Dalam transaksi transfer dana antar bank tanpa biaya administrasi melalui aplikasi Flip akad yang digunakan ialah akad wakalah, maka transaksi ini diperbolehkan, sebagaimana yang terdapat dalam AlQur'an surah Al-Kahfi [18] ayat 19, yakni:

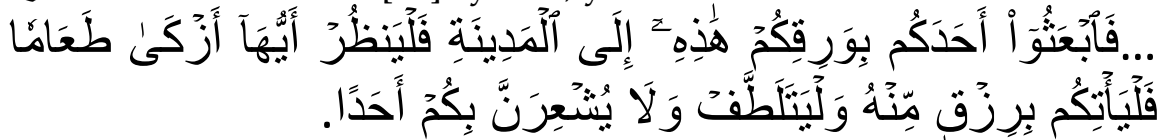

“...Maka suruhlah salah seorang di antara kamu untuk pergi ke kota dengan membawa uang perakmu ini, dan hendaklah dia lihat manakah makanan yang lebih baik, maka hendaklah ia membawa makanan itu untukmu, dan hendaklah ia berlaku lemah-lembut dan janganlah sekali-kali menceritakan halmu kepada seorangpun." (QS. Al-Kahfi [18]:19)

Ayat di atas merupakan cerita penghuni Gua Hira dalam melakukan wakalah untuk membeli makanan (Mubarok \& Hasanuddin, 2017: 167). Maka dengan adanya akad wakalah dapat membantu kebutuhan seseorang dalam melaksanakan suatu urusan, yang mana pada hakikatnya tugas dan tanggung jawab urusan seseorang merupakan kewajibannya sendiri. Namun, terkadang seseorang tidak dapat melaksanakan tugas tersebut karena halangan yang timbul pada dirinya diluar kemampuannya, oleh sebab itu seseorang mewakilkan kepada orang lain yang dianggapnya mampu dan boleh bertindak untuk menyempurnakan tanggung jawab tersebut demi kemaslahatannya (Siregar \& Koeruddin, 2019:254).

Transaksi transfer dana antar bank tanpa biaya administrasi yang dipraktikkan melalui aplikasi Flip di dalam akad telah sah karena sudah memenuhi rukun dan syarat wakalah. Rukun wakalah menurut jumhur ulama kecuali Hanafiyah pada transaksi transfer dana antar bank melalui aplikasi Flip, yaitu sebagai berikut:

1. Pihak yang mewakilkan (muwakkil).

Pada transaksi transfer dana antar bank tanpa biaya administrasi yang dilakukan melalui Flip, maka yang menjadi muwakkil yaitu pengguna aplikasi Flip.

2. Pihak yang mewakili (wakil).

Pada transaksi transfer dana antar bank tanpa biaya administrasi yang dilakukan melalui Flip, maka yang berkedudukan sebagai wakil ialah pihak Flip karena mewakilkan pengguna aplikasi Flip. 
3. Objek wakalah atau sesuatu yang diwakilkan (muwakkal fih)

Dalam hal ini yang menjadi objek wakalah (muwakkal fih) adalah transfer ke rekening bank yang berbeda.

4. Sighat (ijab dan kabul)

Dalam transaksi transfer dana melalui Flip, ijab dan kabul ditunjukkan melalui tindakan dari masing-masing pihak saat proses transaksi dilakukan.

Adapun syarat-syarat wakalah menurut Fatwa DSN MUI No. 10/DSN-MUI/VI/2000 yaitu:

1. Pernyataan sighat (ijab kabul) harus dinyatakan oleh para pihak untuk menunjukkan kehendak mereka dalam mengadakan kontrak (akad). Pada implementasinya, para pihak (pengguna dan Flip) sudah menyatakan ijab dan kabul yang menunjukkan kehendak kedua belah pihak dalam akad wakalah melalui perbuatan dari masing-masing pihak dalam bertransaksi.

2. Pemberi kuasa (muwakkil), syarat-syarat muwakkil di antaranya pemilik sah yang dapat bertindak terhadap sesuatu yang diwakilkan dan orang mukallaf atau anak mumayyiz dalam batasbatas tertentu, yakni dalam hal-hal yang bermanfaat baginya seperti mewakilkan untuk menerima hibah, menerima sedekah dan sebagainya. Pada implementasi transfer dana antar bank tanpa biaya administrasi, persyaratan muwakkil sudah terpenuhi, hal tersebut dapat dilihat saat para pengguna verfikasi akun mengunggah foto KTP, sehingga pengguna termasuk dalam persyaratan tersebut.

3. Penerima kuasa (wakil/yang mewakili), syarat wakil yang harus dipenuhi yaitu: cakap hukum, dapat mengerjakan tugas yang diwakilkan kepadanya, wakil adalah orang yang diberi amanat. Pada implementasinya, persyaratan tersebut sudah terpenuhi di mana pihak Flip berperan sebagai wakil adalah pihak yang memenuhi persyaratan tersebut karena Flip sudah terlisensi dari Bank Indonesia dengan nomor izin 18/196/DKSP/68, Flip juga merupakan pihak yang dipercaya untuk dititipkan uang agar ditransfer ke rekening tujuan yang dibuat oleh pengguna. 
4. Syarat-syarat objek akad yang harus dipenuhi, di antaranya: diketahui dengan jelas oleh orang yang mewakili, tidak bertentangan dengan syariat Islam, dapat diwakilkan menurut syariat Islam. Dalam praktik transfer dana antar bank tanpa biaya administrasi melalui aplikasi Flip, persyaratannya sudah terpenuhi karena telah diketahui secara jelas oleh pihak Flip sebagai wakil bahwa tugas yang diwakilkan ialah transfer ke rekening tujuan yang berbeda dengan rekening milik pengguna sebagai muwakkil, sementara tugas yang diwakilkan tidak bertentangan dengan syariat Islam serta bisa diwakilkan menurut syariat Islam.

Adapun adanya biaya tambahan yang diterapkan Flip ketika melakukan transfer dana yang sudah melewati batas maksimal nominal transaksi per hari, seperti dalam sehari sudah melakukan transfer sebesar Rp5.000.000,00 atau sudah mencapai batas maksimal menggunakan transaksi instan per bulan yang diterapkan dalam praktik transaksi, maka dalam fikih muamalah transaksi seperti ini mengandung unsur wakalah bi al-ujrah. Akad wakalah bi al-ujrah yang terjadi pada transaksi transfer dana melalui aplikasi Flip ialah akad perwakilan antara pengguna Flip dengan pihak Flip untuk melaksanakan transfer sejumlah nominal transfer dengan memberikan upah (fee) yang berhak diterima oleh pihak Flip yang sudah menjadi wakil dalam transaksi transfer dana. Kemudian terkait analisis ketentuan-ketentuan ujrah berdasarkan Fatwa DSN MUI Nomor 113/DSN-MUI/IX/2017 tentang Wakalah bi al-Ujrah dapat diterangkan sebagai berikut:

1. Ujrah boleh berupa uang atau barang yang boleh dimanfaatkan menurut syariah dan peraturan perundang-undangan yang berlaku. Dalam praktiknya, pada proses transfer dana ke bank yang berbeda melalui aplikasi Flip, ujrah-nya berupa uang.

2. Kuantitas dan kualitas ujrah harus jelas, baik berupa angka nominal, presentase tertentu, atau rumus yang disepakati dan diketahui para pihak yang melakukan akad. Dalam praktiknya, pada proses transfer dana ke bank yang berbeda melalui aplikasi Flip, kuantitas ujrah yang ditetapkan yaitu sebesar Rp2.500,00 untuk transaksi transfer dana yang melebihi batas maksimal 
transaksi per hari dan sebesar Rp500,00 untuk transaksi transfer dana yang melebihi batas maksimal transfer dana secara instan.

3. Ujrah boleh dibayar secara tunai, angsur/bertahap, dan tangguh sesuai dengan syariah, kesepakatan, dan/atau peraturan perundang-undangan yang berlaku. Dalam praktiknya, pada proses transfer dana ke bank yang berbeda melalui aplikasi Flip, ujrah-nya dibayar secara tunai, yaitu saat melakukan transaksi melebihi batas maksimal yang sudah ditentukan oleh pihak Flip. Maka saat melakukan transfer dana harus menambahkan ujrah sesuai dengan kesepakatan berdasarkan ketentuan yang belaku, selain dari sejumlah nominal transfer dana yang ingin ditransfer dan kode unik transaksi.

4. Ujrah yang telah disepakati boleh ditinjau ulang atas manfaat yang belum diterima oleh muwakkil sesuai kesepakatan. Dalam aplikasi Flip terdapat menu "Bantuan" yang mana pada menu tersebut dijabarkan bahwa jika terdapat kendala seperti dana belum samapi ke rekening tujuan, maka pengguna dapat mengonfirmasi kepada pihak Flip dengan mengirimkan foto/screenshot daftar/riwayat mutasi dari rekening penerima pada tanggal transaksi selesai diproses ke chat bantuan atau $e$ mail (hello@flip.id). Setelah itu, Flip akan mengonfirmasi ke bank yang bersangkutan mengenai hal tersebut (Zendesk, 28 Maret 2021). Hal tersebut adalah salah satu contoh suatu kondisi yang sesuai dengan ketentuan yang telah disebutkan bahwa bila pengguna (muwakkil) belum menerima manfaat sesuai kesepakatan, maka ujrah-nya boleh ditinjau ulang sampai pengguna menerima manfaat tersebut. Tetapi dalam praktiknya, hal seperti itu amat jarang terjadi karena setiap transaksi yang terjadi pada aplikasi Flip mayoritas berhasil dan pengguna selalu mendapatkan bukti transfer setelah transaksi berhasil yang dikirim ke aplikasi Flip dan e-mail pengguna berupa notifikasi yang dapat diunduh. 


\section{PENUTUP}

\section{Kesimpulan}

Berdasarkan pemaparan yang telah dikemukakan pada bab sebelumnya terkait transaksi transfer dana antar bank tanpa biaya administrasi melalui aplikasi Flip, dapat disimpulkan sebagai berikut:

1. Praktik transaksi transfer dana antar bank melalui aplikasi Flip telah diterapkan dengan tepat menggunakan akad perwakilan (wakalah). Adapun mekanisme yang digunakan untuk transfer dana yaitu pengguna cukup mengikuti prosedur transaksi yang ingin dilakukan dengan cara mengisi data permintaan transfer, kemudian melakukan transfer dana sejumlah nominal yang ingin dikirim ditambah kode unik ke rekening bank Flip yang sama dengan bank pengguna, setelah transfer ke Flip berhasil, Flip akan mengirimkan uang yang tersedia di rekening bank Flip lainnya yang sama dengan bank tujuan pengguna, lalu mengirim bukti transfer dana melalui aplikasi Flip dan e-mail pengguna. Dalam penambahan kode unik pengguna tidak merasa keberatan, pengguna rela menambahkan kode unik karena nominal kode unik lebih kecil daripada biaya administrasi konvensional.

2. Berdasarkan analisis fikih muamalah transaksi transfer dana antar bank melalui aplikasi Flip diperbolehkan karena transaksi yang dilakukan terhindar dari transaksi riba, maisir, gharar, tadlis serta terdapat kemaslahatan untuk meringankan transaksi transfer dana antar bank yang berbeda. Selain itu, akad yang digunakan juga sudah sesuai dengan Fatwa DSN MUI No. 10/DSN-MUI/IV/2000 tentang Wakalah dan Fatwa DSN MUI No. 113/DSN-MUI/IX/2017 tentang Wakalah bi al-Ujrah. Adapun untuk penyerahan kode unik yang belum mencapai Rp10.000,00 pengguna dapat melakukan pengisian saldo ke akun pengguna dengan minimal pengisian saldo Rp10.000,00, setelah saldo masuk ke akun pengguna, pengguna dapat melakukan penarikan saldo. Dengan demikian tidak terjadi gharar dalam penyerahan kode unik, karena kode unik langsung dapat ditarik bersama dengan saldo yang ada di akun Flip pengguna.

\section{Saran}

Analisis Fikih Muamalah Terhadap Transaksi Transfer Dana Antar Bank Melalui Aplikasi Flip

Siti Widya Umiyati, Selvi Nur Fitriah 
Setelah mengetahui praktik transaksi transfer dana antar bank tanpa biaya administrasi melalui aplikasi Flip, penulis menyarankan sebagai berikut:

1. Penulis menyarankan kepada pihak Flip agar dapat memproses transaksi transfer dana dengan lebih cepat agar pengguna tidak harus menunggu lama dan menambahkan jam operasional transaksi agar pengguna dalam melakukan transaksi transfer dana melalui aplikasi Flip kapan pun.

2. Penulis menyarankan kepada para pengguna Flip yang menggunakan aplikasi Flip untuk transfer dana, agar lebih memperhatikan tata cara pengiriman yang benar sebelum melakukan transaksi agar proses transaksi dilakukan dengan lebih cepat.

3. Penulis menyarankan untuk penelitian selanjutnya agar lebih memperbanyak referensi dan sumber-sumber terpercaya, seperti melakukan wawancara kepada pihak Flip atau penyedia layanan lainnya sehingga dapat memberikan informasi beserta data yang lebih akurat dan tepat.

\section{DAFTAR PUSTAKA}

Al-Bukhari, Abu 'Abdillah Muhammad bin Isma'il. (2002). Shahih alBukhari. Beirut: Dar Ibnu Katsir.

Al-Jaziri, Abdurrahman. (1996). Figh Empat Madzhab Bagian Muamalah II. Jilid 6. Jakarta: Darul Ulum Press.

Al-Khalidi, Shalah 'Abdul Fattah. (2019). Mudah Tafsir Ibnu Katsir. terj. Engkos Kosasih, dkk. Jilid 2. Jakarta Timur: Maghfirah Pustaka.

Al-Sheikh, Abdullah bin Muhammad bin Abdurrahman bin Ishaq. (2004). Lubaabut Tafsir min Ibnu Katsir. terj. M. Abdul Ghoffar E.M., Abdurrahim Mu'thi, Abu Ihsan Al-Atsari. Jilid 1. Bogor: Pustaka Imam Asy-Syafi'i.

Az-Zuhaili, Wahbah. (2011). Fiqih Islam Wa Adillatuhu. terj. Abdul Hayyie al-Kattani, dkk. Jilid 5. Jakarta: Gema Insani.

Cahyani, Intan Putri. (2002). Membangun Engagement Melalui Platform

Digital (Studi Kasus Flip Sebagai Start-Up Fintech), Jurnal Ilmu Komunikasi, 3(2).

Analisis Fikih Muamalah Terhadap Transaksi Transfer Dana Antar Siti Widya Umiyati, Selvi Nur Fitriah Bank Melalui Aplikasi Flip 59 
Dwimurti, Bangun Seto. (2020). Transaksi Dana Beda Bank Tanpa Biaya Administrasi Melalui Aplikasi Flip Dalam Tinjauan Etika Bisnis Islam, Jurnal Al-Hakim: Jurnal Ilmiah Mahasiswa, Studi Syariah, Hukum dan Filantropi, 2(2).

Flip, "Bagaimana cara top up saldo Flip?", Website Flip, 16 Juni 2021. https://flipid.zendesk.com/hc/id/articles/360021130771Bagaimana-cara-top-up-saldo-Flip- (2 Agustus 2021)

Flip, "Perjalanan dari 40 ke 3,5 juta pengguna", Instagram Flip, 8 Januari 2021. https://www.instagram.com/p/CJyCxjDhP3I/ (10 Maret 2021)

Flip, "Transaksi saya sudah berhasil, tapi penerima menginfokan bahwa belum menerima dananya", Website Flip, 28 Maret 2021, https://flipid.zendesk.com/hc/id/articles/360021132031-

Transaksi-saya-sudah-berhasil-tapi-penerima-menginfokanbahwa-belum-menerima-dananya (19 Agustus 2021)

Hosen, M. Nadratuzzaman. (2009). Analisis Bentuk Gharar Dalam Transaksi Ekonomi, Al-Iqtishad, 1(1).

Ibrahim, Duski. (2019). Al-Qawa'id Al-Fiqhiyah (Kaidah-Kaidah Fiqih). Palembang: CV. Amanah.

Indonesia, Peraturan Bank Indonesia Tentang Penyelenggaraan Teknologi Finansial. PBI No. 19/12/PBI/2017, TLN No. 6142.

Indonesia, Peraturan Bank Indonesia Tentang Transfer Dana, PBI No. 14/23/PBI/2012, TLN No. 5381.

Indonesia, Undang-Undang tentang Perbankan Syariah, UU Nomor 21 Tahun 2008, TLN No. 4867.

Indonesia, Undang-Undang tentang Transfer Dana, UU Nomor 3 Tahun 2011, LN No. 39 tahun 2011.

Juanda. (2019). Fiqih Muamalah Prinsip-Prinsip Bermuamalah Secara Syar'i. Temanggu: Desa Pustaka Indonesia.

Khalil, Abdul Wahab. (2014). Transfer Dana Dalam Perspektif Hukum Islam, Jurnal Al-Hurriyah, 15(2).

Kusumawardhani, Arini. (2017). Strategi Viral Marketing PT Flip Menggunakan Electronik Word Of Mouth Dalam Pembentukan Brand Awareness (www.Flip.id), Skripsi: Universitas Telkom Bandung.

Margono, Novindo Suyud. (2009). Kompilasi Hukum Ekonomi Syariah. Jakarta: Novindo Pustaka Mandiri.

60 Analisis Fikih Muamalah Terhadap Transaksi Transfer Dana Antar Bank Melalui Aplikasi Flip

Siti Widya Umiyati, Selvi Nur Fitriah 
Munawwir, Ahmad Warson. (1997). Kamus Al-Munawwir ArabIndonesia Terlengkap. Surabaya: Pustaka Progressif.

Putri, Athiyyah Anisa. (2020). Pengaruh Kemudahan Penggunaan, Kemanfaatan, dan Kepercayaan Majelis Taklim Hayatul Ilmi Surabaya Terhadap Minat Menggunakan Flip.id dengan Perspektif Hifdzul Mal, Skripsi: Prodi Ekonomi Syariah, Fakultas Ekonomi dan Bisnis Islam Universitas Islam Negeri Sunan Ampel, Surabaya.

Sabiq, Sayyid. (2009). Fikih Sunnah. Jilid 5. Jakarta: Cakrawala Publishing.

Shihab, M. Quraish. (2002). Tafsir Al-Misbah Pesan, Kesan dan Keserasian al-Qur'an. Volume 3. Tangerang: Lentera Hati.

Siregar, Hariman Surya dan Koko Khoerudin. (2019). Fikih Muamalah Teori dan Implementasi. Bandung: Remaja Rosdakarya.

Septika, Cintya Ega. (2018). Analisis Faktor-Faktor yang Mempengaruhi Minat untuk Menggunakan Aplikasi Transfer Antar Rekening Bank Gratis dengan Flip (Studi Kasus pada Mahasiswa Fakultas Ekonomi dan Bisnis Islam UIN Sunan Kalijaga Yogyakarta), Skripsi: Mahasiswa Prodi Perbankan Syari'ah, Fakultas Ekonomi dan Bisnis Islam, Universitas Islam Negeri Sunan Kalijaga, Yogyakarta.

Soemitra, Andri. (2019). Hukum Ekonomi Syariah dan Fiqh Muamalah di Lembaga Keuangan dan Bisnis Kontemporer. Jakarta: Kencana.

Wawancara dengan pengguna Flip, Ade Fatimah. Jakarta, 12 Juli 2021. Wawancara dengan pengguna Flip, Arfiyah Noviyanti. Jakarta, 12 Juli 2021.

Wawancara dengan pengguna Flip, Euis Nurhayati. Jakarta, 11 Juli 2021.

Wawancara dengan pengguna Flip, Fatimah. Jakarta, 11 Juli 2021.

Wawancara dengan pengguna Flip, Hastyn. Jakarta, 11 Juli 2021.

Wawancara dengan pengguna Flip, Mela Angelina. Jakarta 11 Juli 2021. Wawancara dengan pengguna Flip, Salsabila. Jakarta, 15 Juli 2021. Wawancara dengan pengguna Flip, Sonia Rahmayani. Jakarta, 13 Juli 2021. 